\title{
Väkirehun kasviöljyn ja E-vitamiinin vaikutus naudanlihan koostumukseen
}

\author{
Merja Manninen ${ }^{1)}$, Merja Holma ${ }^{2)}$, Lauri Jauhiainen ${ }^{1)}$ ja Marjatta Suvitie ${ }^{3)}$ \\ ${ }^{1)}$ MTT, 31600 Jokioinen, merja.manninen@mtt.fi \\ ${ }^{2)}$ Rehuraisio Oy, 21201 Raisio,merja.holma@raisiogroup.com \\ ${ }^{3)}$ MTT, 71750 Maaninka, marjatta.suvitie@mtt.fi
}

\section{Johdanto}

Konjugoituneen linolihapon lähteitä ovat märehtijäperäiset tuotteet. CLA:n positiiviset vaikutukset ravitsemuksessa ovat hyvin tunnettuja. Sen on todettu mm. ehkäisevän syöpää ja sydän- ja verisuonitauteja (Ip ym. 1994, Lee ym. 1994). Lihan CLA-pitoisuus on noussut lisäämällä ruokintaan kasviperäisiä öljyjä (Enser ym. 1999, Griinari ym. 2000). Naudanlihassa cis-9,trans-11-isomeerin osuus kokonais-CLA:sta on noin 60\% (Shantha ym. 1994). Linolihappo muuttuu pötsissä CLA:ksi, josta osa pääsee kudoksiin saakka, osa muuttuu pötsissä välivaiheiden kautta tyydyttyneeksi steariinihapoksi. Monityydyttymättömien rasvahappojen lisääntyessä lihassa riskinä on, että etenkin varastoitaessa lihan hapettumisherkkyys kasvaa. Hapettuminen voi aiheuttaa ongelmia naudanlihaa prosessoitaessa ja varastoitaessa: raa an lihan väri muuttuu ruskehtavaksi ja lihan tuoksu voi kehittyä epämiellyttäväksi. Pitkään varastoidussa lihassa voi ilmetä myös makuvirheitä. Rehun Evitamiinilisäyksellä on useissa kokeissa (mm. Sheeny ym. 1997) voitu estää tai hidastaa rasvan hapettumista. Lisäksi E-vitamiini on parantanut lihan väriä. Tämä tutkimus selvitti väkirehun soijaöljylisän, E-vitamiinilisän ja niiden molempien vaikutusta naudanlihan rasvahappokoostumukseen, lihan aistinvaraiseen laatuun sekä lihan värimuutoksiin. Sonnit saivat säilörehua vapaasti ja täysrehua 2,0-4,0 kg KA/d. Teuraspainotavoite oli $350 \mathrm{~kg}$.

\section{Aineisto ja menetelmät}

\section{Eläinaines, tuotanto-olosuhteet, rehut ja ruokinta}

Kokeessa oli 32 5.3.-28.4.2000 MTT:n emolehmänavetalla syntynyttä hf-sonnivasikkaa, isinä hfsonnit Teristen Jesse (13), Koskis Noak (11) ja Thorsvik Kentauri (8). Koe alkoi 12.10.2000, jolloin sonnit olivat keskimäärin $6,5 \mathrm{kk}$ ja $291 \mathrm{~kg}$. Sonnit olivat neljän eläimen karsinoissa ja ne punnittiin neljän viikon välein. Rehuina olivat nurmisäilörehu (SR) ja neljä täysrehua: kontrolli (K), soijaöljypitoinen (S), E-vitamiinipitoinen (E) ja molempia sisältävä rehu (SE). E-vitamiinilisäys K- ja Srehuihin oli 25 ja E- ja SE-rehuihin $375 \mathrm{mg} / \mathrm{kg}$. Soijaöljyä S- ja SE-rehuihin lisättiin 4\%, kun kaupallisessa mullinrehussa se on noin 1\%. Timotei-nurminata-apila-kasvusto (60-30-10\%) kaadettiin 19.-21.6.2000 niittomurskaimella, esikuivattiin ja paalattiin. Säilöntään käytettiin AIV 2 Plus -liuosta 5 l/t. Eläimet saivat $S R$ ja vettä vapaasti ja väkirehua ensimmäiset $55 \mathrm{~d} 2,0(A l)$, seuraavat 56 d 3,0 (Ke) ja loppukasvatuksen (keskimäärin 114 d) ajan 4,0 kg KA/eläin/d (Lo). Rehut analysoitiin MMT:n eläinravitsemuksen laboratoriossa. SR:sta analysoitiin kuiva-aine (KA), tuhka, raakaproteiini, NDF-kuitu (Van Soest ym. 1991) ja OA:n in vitro -sellulaasisulavuus (Friedel 1990). Täysrehun rehuarvo laskettiin raaka-ainekoostumuksen perusteella (Tuori ym. 2000) ja Evitamiinipitoisuus määritettiin MTT:n Kemian laboratoriossa nestekromatografilla.

\section{Teurastus, ruhon ja lihan laatu}

Sonnit teurastettiin Kiteen opetusteurastamossa ja ruhot EUROP-luokitettiin. Ulkofileestä määritettiin loppu-pH 36-48 h teurastuksesta. Ulkofileestä leikattiin $30 \mathrm{~cm}: n$ pala, joka toimitettiin LTK:een aistinvaraiseen arvosteluun, konsistenssi- ja värimääritykseen $(0,5,10,15,20,30$ d). Myoglobiinipitoisuus mitattiin kahdesti ( 0 ja 30 d). Näytettä raakakypsytettiin $14 \mathrm{~d}+2 \pm 1^{\circ} \mathrm{C}$ ennen pakastusta. Ulkofileen proteiini- ja rasvapitoisuus määritettiin MTT:n Eläinravitsemuksella ja E-vitamiinipitoisuus MTT:n Kemian laboratoriossa nestekromatografilla. Jauhelihan raaka-aineeksi leikattiin niskapalaa 2 $\mathrm{kg}$ ja rasvaa $0,5 \mathrm{~kg}$, jotka vakumoitiin, pakastettiin ja toimitettiin LTK:een. Raaka-aineista tehtiin jauheliha tavoitteena $15 \%$ rasvapitoisuus. Jauhelihan väri määritettiin 4 kertaa $(0,5,10$ ja 15 d) ja

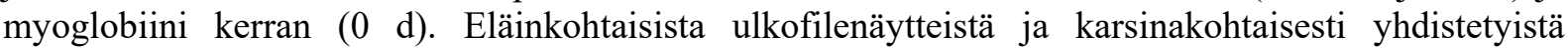
jauhelihanäytteistä määritettiin rasvapitoisuus Buchi -uuttolaitteella Raisio Yhtymän tutkimuslaboratoriossa. Rasvahapot analysoitiin kaasukromatografilla metyyliestereinä (Bannon ym. 1982, AOCS Ce 1c-89). Tulokset laskettiin yksittäisten rasvahappojen osuutena (\%) kokonaisrasvahapoista. 


\section{Tilastollinen käsittely}

Koe suoritettiin satunnaistettujen täydellisten lohkojen koeasetelman mukaisesti eli eläimet jaettiin kokeen alussa elopainon perusteella kahteen lohkoon. Lohkon sisällä eläimet jaettiin satunnaisesti neljään karsinaan (a 4 eläintä), joihin jokaiseen kohdistettiin yksi neljästä käsittelystä. Aineisto analysoitiin tilastollisesti satunnaistettujen lohkojen varianssianalyysin avulla ottamalla ruokintoja testattaessa virhetermiksi ruokinta x karsina -yhdysvaikutus, mikä toimi myös jäännösvirheenä, kun kustakin karsinasta oli vain yksi havainto tai mittaus. Kun mittaukset oli tehty eläimittäin, malli sisälsi ruokinta x karsina -yhdysvaikutuksen lisäksi myös erillisen jäännösvirheen, jota ei kuitenkaan käytetty testauksessa virheterminä. Tilastollinen analysointi suoritettiin SAS-ohjelmistolla (1999, versio 8.2).

\section{Tulokset ja tulosten tarkastelu}

Koe kesti keskimäärin 225 d. Eläinten terveys oli moitteeton. SR:n KA-pitoisuus oli $231 \mathrm{~g}$ ja D-arvo 69,7\%. KA-kilo sisälsi raakavalkuaista $166 \mathrm{~g}$ ja OIV:sta $85 \mathrm{~g}$. Säilönnällinen laatu oli hyvä ja pH 4,01. K- ja E-rehujen energiapitoisuus oli 1,05 ja S- ja SE-rehujen 1,12 RY/kg KA. K- ja E-rehut sisälsivät rasvaa 31 ja 33 ja S- ja SE-rehut 72 ja 74 g/kg KA. K- ja S-rehujen E-vitamiinipitoisuus oli 22,7 ja Eja SE-rehujen 349,3 ja 318,5 mg/kg KA. Eläinten syönti ja ravintoaineiden saanti oli yhdenmukainen (Taulukko 1). Kokeen aikana kasvu oli keskimäärin 1557 ja loppujaksolla peräti $1684 \mathrm{~g} / \mathrm{d}$. E-sonnit rasvoittuivat SE-sonneja vähemmän $(\mathrm{p}<0,10,2,9$ vs. 3,4).

Taulukko 1. Sonnien syönti ja energian saanti $(n=8)$, kasvu, teurastulokset ja rehun muuntosuhde $(n=32)$.

\begin{tabular}{|c|c|c|c|c|c|c|c|c|c|c|}
\hline \multirow[t]{2}{*}{ Ruokinta } & \multirow[t]{2}{*}{$\mathrm{K}$} & \multirow[t]{2}{*}{$\mathrm{S}$} & \multirow{2}{*}{\multicolumn{2}{|c|}{ E SE }} & \multirow[t]{2}{*}{$\mathrm{SEM}^{2}$} & \multicolumn{5}{|c|}{ Merkitsevyys ${ }^{1}$} \\
\hline & & & & & & $\mathrm{K} v s \mathrm{~S}$ & $\mathrm{~K} v s \mathrm{E}$ & $\mathrm{K} v S \mathrm{SE}$ & SvsSE & EvsSE \\
\hline Kg KA, Säilörehu & 5,3 & 5,2 & 5,4 & 5,20 & 0,246 & & & & & \\
\hline Väkirehu & 3,2 & 3,2 & 3,2 & 3,26 & 0,037 & & * & & & \\
\hline Yhteensä & 8,5 & 8,4 & 8,6 & 8,46 & 0,213 & & & & & \\
\hline RY & 8,4 & 8,6 & 8,5 & $55 \quad 8,60$ & 0,203 & & & & & \\
\hline Raakavalkuainen, g & 1566 & 1532 & 1571 & 1543 & 36,5 & & & & & \\
\hline NDF, g & 3422 & 3300 & 3433 & 3334 & 103,8 & o & & & & \\
\hline OIV, g & 847 & 824 & 852 & 824 & 17,5 & o & & o & & * \\
\hline Paino kokeen lopussa, $\mathrm{kg}$ & 636 & 641 & 640 & 638 & 3,5 & & & & & \\
\hline Teuraspaino, kg & 349 & 350 & 348 & 352 & 2,6 & & & & & \\
\hline Ikä kokeen lopussa & 433 & 421 & 417 & 421 & 4,3 & & & & & \\
\hline \multicolumn{11}{|l|}{ Kasvu, g/d } \\
\hline $\mathrm{Al}$ & 1318 & 1397 & 1251 & 1337 & 78,1 & & & & & \\
\hline $\mathrm{Ke}$ & 1468 & 1558 & 1676 & 1556 & 80,6 & & & & & \\
\hline Lo & 1576 & 1742 & 1769 & 1651 & 100,1 & & & & & \\
\hline Kokeen aikana & 1486 & 1596 & 1599 & 1547 & 51,6 & & & & & \\
\hline Nettokasvu ${ }^{3}$ & 879 & 936 & 927 & 920 & 31,5 & & & & & \\
\hline Teuras-\% & 55,0 & 54,7 & $7 \quad 54,4$ & $4 \quad 55,1$ & 0,15 & & & & & \\
\hline Lihakkuus ${ }^{4}$ & 7,6 & 7,4 & 6,4 & 7,4 & 0,20 & & o & & & \\
\hline Rasvaisuus $^{5}$ & 3,3 & 3,1 & 2,9 & 3,4 & 0,09 & & & & & o \\
\hline \multicolumn{11}{|l|}{ Rehun muuntosuhde } \\
\hline Kg KA/lisäkasvu-kg & 5,8 & 5,3 & 5,4 & 5,48 & 0,198 & & & & & \\
\hline Kg KA/nettokasvu-kg & 9,8 & 9,1 & 9,4 & 9,24 & 0,369 & & & & & \\
\hline RY/lisäkasvu-kg & 5,7 & 5,4 & 5,4 & 5,57 & 0,196 & & & & & \\
\hline RY/nettokasvu-kg & 9,6 & 9,2 & 9,3 & 9,40 & 0,366 & & & & & \\
\hline
\end{tabular}

Ulkofileen proteiini- ja rasvapitoisuus oli keskimäärin 835 ja 141 g/kg KA (Taulukko 2). Väkirehun Evitamiinilisäys nosti lihan E-vitamiinipitoisuutta selvästi ollen parhaimmillaan yli kaksinkertainen $(\mathrm{p}<0,01, \mathrm{~K}$ vs. SE). Ulkofileen aistinvaraisessa arvostelussa näytteet arvioitiin normaaleiksi, ainoastaan SE-lihan mehukkuus oli hieman parempi kuin E-lihan $(\mathrm{p}<0,10,5,1$ vs. 4,3). Ulkofileen myoglobiinipitoisuus oli sulatuspäivänä keskimäärin $6,9 \mathrm{mg} / \mathrm{g}$ ja kuukautta myöhemmin se oli alentunut todennäköisimmin valuman johdosta $1,5 \mathrm{mg} / \mathrm{g}$. Tuoreen jauhelihan myoglobiinipitoisuus valmistuspäivänä oli keskimäärin $6,2 \mathrm{mg} / \mathrm{g}$ mikä on naudanlihalle normaali taso. 30 päivän kuluttua myoglobiini oli alentunut merkittävästi. Tässä yhteydessä olisi ollut hyödyllistä määrittää lihan valuma. Ulkofileen loppu-pH oli keskimäärin 5,6 ja kaikkien ruhojen ulkofileen loppu-pH oli alle 6,00 eli tervalihaprosentti oli 0 . 
Taulukko 2. Ulkofileen koostumus $(n=8)$, aistinvarainen laatu $(n=32)$ ja myoglobiinipitoisuus $(n=32)$.

\begin{tabular}{|c|c|c|c|c|c|c|c|c|c|c|}
\hline \multirow[t]{2}{*}{ Ruokinta } & \multirow[t]{2}{*}{$\mathrm{K}$} & \multirow[t]{2}{*}{$\mathrm{S}$} & \multirow[t]{2}{*}{$\mathrm{E}$} & \multirow[t]{2}{*}{$\mathrm{SE}$} & \multirow[t]{2}{*}{$\mathrm{SEM}^{2}$} & \multicolumn{5}{|c|}{ Merkitsevyys $^{1}$} \\
\hline & & & & & & $\mathrm{K} v s \mathrm{~S}$ & $\mathrm{~K} v s \mathrm{E}$ & $\mathrm{K} v s \mathrm{SE}$ & $\mathrm{S} v s \mathrm{SE}$ & $\mathrm{E} v s \mathrm{SE}$ \\
\hline Prim. KA, g/kg & 261 & 262 & 263 & 266 & 5,4 & & & & & \\
\hline Proteiini, g/kg KA & 842 & 837 & 844 & 818 & 21,4 & & & & & \\
\hline Raakarasva, g/kg KA & 131 & 138 & 134 & 161 & 19,9 & & & & & \\
\hline E-vit. tuoreessa, mg/100g & 0,14 & 0,15 & 0,24 & $+\quad 0,31$ & 0,011 & & $* *$ & $* *$ & $* *$ & $*$ \\
\hline \multicolumn{11}{|c|}{ Ulkofileen laatuanalyysit, aistinvarainen arvio ${ }^{3}$} \\
\hline Mureus & 4,9 & 5,2 & 5,0 & 5,1 & 0,21 & & & & & \\
\hline Mehukkuus & 4,8 & 4,7 & 4,3 & 5,1 & 0,14 & & & & & o \\
\hline Maku & 4,9 & 4,7 & 5,0 & 5,1 & 0,08 & & & & & \\
\hline Konsistenssi ${ }^{4}$ & 9,45 & 8,73 & 9,17 & 8,76 & $\mathrm{na}^{5}$ & & & & & \\
\hline Myoglobiini $0 \mathrm{~d}, \mathrm{mg} / \mathrm{g}$ & 7,3 & 6,7 & 7,0 & 6,7 & 0,22 & & & & & \\
\hline Myoglobiini $30 \mathrm{~d}, \mathrm{mg} / \mathrm{g}$ & 5,8 & 5,5 & 5,5 & 5,0 & 0,90 & & & & & \\
\hline Ulkofileen $\mathrm{pH}_{24}$ & 5,5 & 5,6 & 5,6 & 5,7 & 0,03 & & & & & \\
\hline
\end{tabular}

${ }_{1}$ o $\mathrm{p}<0,10 ; * \mathrm{p}<0,05 ; * * \mathrm{p}<0,01 ; * * * \mathrm{p}<0,001 .{ }^{2}$ Keskiarvon keskivirhe (Standard error of mean).

${ }^{3}$ Aistinvarainen arvio: asteikko 1-7, esim. $7=$ erittäin murea...1=erittäin sitkeä, $5=$ normaali.

${ }^{4}$ Vastus lihapalaa leikatessa, normaali 8-10, sitkeä $>10 .{ }^{5}$ Not available.

Rehun E-vitamiinilisäys ei vaikuttanut ulkofileen ja jauhelihan vaaleus- eli L-arvoihin (Taulukko 3). Alussa $(0$ d) ulkofile luokiteltiin tummahkoksi $(38,3)$ muuttuen viimeiseen mittausajankohtaan mennessä normaaliksi $(44,5)$, mihin todennäköisimmin vaikutti valuman myötä poistunut myoglobiini. Jauhelihan L-arvot pysyivät eri mittausajankohtina tasaisina ja käytännössä jauheliha hyvin tummana $(0 \mathrm{~d}: 50,9 \rightarrow 15 \mathrm{~d}: 52,5)$. Naudanlihan luokittelu L-arvojen perusteella on kuitenkin melko epäluotettavaa, sillä selvää raja-arvoa ei ole olemassa. Naudanlihan väriin eli tummuuteen vaikuttavat $\mathrm{mm}$. lihan hapetusaste, naudan rotu, sukupuoli ja ikä. Kontrollien korkeimman myoglobiinipitoisuuden johdosta niiden ulkofile oli tummin (pienin $\mathrm{L}^{*}$-arvo) ja punaisin (suurin $\mathrm{a}^{*}$-arvo). Valuman määrittäminen olisi voinut selventää lihan värimuutoksia varastoinnin jälkeen.

Taulukko 3. Ulkofileen $(n=32)$ ja jauhelihan $(n=8)$ väri.

\begin{tabular}{|c|c|c|c|c|c|c|c|c|c|}
\hline \multirow[t]{2}{*}{ Ruokinta } & \multirow[t]{2}{*}{$\mathrm{K}$} & \multirow[t]{2}{*}{$\mathrm{S}$} & \multirow[t]{2}{*}{$\mathrm{E}$} & \multirow[t]{2}{*}{ SE } & \multirow[t]{2}{*}{$\mathrm{SEM}^{2}$} & \multicolumn{3}{|c|}{ Merkitsevyys $^{1}$} & \multirow[b]{2}{*}{ EvsSE } \\
\hline & & & & & & $\mathrm{K} v s \mathrm{E}$ & $\mathrm{K} v s \mathrm{SE}$ & $\mathrm{S} v s \mathrm{SE}$ & \\
\hline \multicolumn{10}{|c|}{ Ulkofileen vaaleus $(\mathrm{L})^{3}, \mathrm{~d}$} \\
\hline 0 & 36,8 & 39,4 & 38,2 & 38,9 & 0,57 & & & & \\
\hline 5 & 40,9 & 41,5 & 41,7 & 41,6 & 0,79 & & & & \\
\hline 10 & 42,1 & 43,7 & 43,4 & 43,4 & $0,52-0,56$ & & & & \\
\hline 15 & 42,6 & 42,4 & 42,8 & 44,6 & 1,09 & & & & \\
\hline 20 & 43,4 & 43,9 & 43,7 & 45,1 & 0,83 & & & & \\
\hline 30 & 44,0 & 44,2 & 44,3 & 45,5 & 1,13 & & & & \\
\hline \multicolumn{10}{|c|}{ Ulkofileen punaisuus $\left(\mathrm{a}^{+}\right)^{4}, \mathrm{~d}$} \\
\hline 0 & 24,8 & 25,8 & 26,1 & 26,0 & 0,81 & & & & \\
\hline 5 & 27,9 & 27,4 & 28,4 & 28,4 & 0,96 & & & & \\
\hline 10 & 29,0 & 28,3 & 27,3 & 29,4 & $1,43-1,54$ & & & & \\
\hline 15 & 28,4 & 27,3 & 26,6 & 27,3 & 1,34 & & & & \\
\hline 20 & 27,5 & 26,1 & 26,1 & 26,7 & 0,37 & & & & \\
\hline 30 & 26,9 & 25,5 & 24,8 & 25,4 & 0,88 & & & & \\
\hline \multicolumn{10}{|c|}{ Jauhelihan vaaleus $(\mathrm{L})^{3}, \mathrm{~d}$} \\
\hline 0 & 50,7 & 50,4 & 51,7 & 50,6 & 0,85 & & & & \\
\hline 5 & 50,0 & 49,9 & 50,6 & 52,4 & 1,50 & & & & \\
\hline 10 & 54,0 & 52,7 & 54,2 & 52,4 & 0,84 & & o & & $*$ \\
\hline 15 & 52,4 & 51,7 & 52,2 & 53,5 & 0,73 & & & & \\
\hline \multicolumn{10}{|c|}{ Jauhelihan punaisuus $(a+)^{4}, d$} \\
\hline 0 & 23,3 & 26,3 & 25,4 & 25,9 & 1,36 & & & & \\
\hline 5 & 29,4 & 29,3 & 29,5 & 29,1 & 1,23 & & & & \\
\hline 10 & 30,7 & 30,7 & 30,2 & 30,5 & 0,81 & & & & \\
\hline 15 & 30,5 & 30,0 & 29,1 & 29,1 & 0,48 & & & & \\
\hline
\end{tabular}

${ }_{1}$ o $\mathrm{p}<0,10 ; * \mathrm{p}<0,05 ; * * \mathrm{p}<0,01 ; * * * \mathrm{p}<0,001 .{ }^{2}$ Keskiarvon keskivirhe (Standard error of mean).

${ }^{3}$ Normaali arvo 39-54, mahdollisesti tervaliha $\mathrm{L}<34 .{ }^{4}$ Myoglobiinin arvo, mitä korkeampi, sitä punaisempi.

Soijaöljylisä muutti sekä ulkofileen että jauhelihan rasvahappokoostumusta huomattavasti. Tyydytty- 
neiden rasvahappojen määrä väheni ja tyydyttymättömien lisääntyi. Soijaöljy lisäsi C18:1 trans rasvahappojen osuutta kokonaisrasvahapoista K- ja E-rasvahappokoostumukseen verrattuna merkitsevästi sekä ulkofileen että jauhelihan kohdalla (Taulukko 4). Ulkofileessä CLA:n osuus rasvahapoista oli S-ruokinnalla suuntaa antavasti korkeampi kuin K-ruokinnalla ( $<<0,10,0,92 v s$. 0,53). S- ja SE-jauhelihan rasvahappokoostumuksesta CLA:n osuus oli K-jauhelihan koostumukseen verrattuna merkitsevästi $(\mathrm{p}<0,05,1,15$ ja 1,20 vs. 0,83$)$ suurempi, myös SE:n CLA-pitoisuus poikkesi merkitsevästi E:n pitoisuudesta ( $\mathrm{p}<0,05,1,20$ vs. 0,76).

\begin{tabular}{|c|c|c|c|c|c|c|c|c|c|c|}
\hline \multirow[t]{2}{*}{ Ruokinta } & \multirow[t]{2}{*}{$\mathrm{K}$} & \multirow[t]{2}{*}{$\mathrm{S}$} & \multirow[t]{2}{*}{$\mathrm{E}$} & \multirow[t]{2}{*}{ SE } & \multirow[t]{2}{*}{$\mathrm{SEM}^{2}$} & \multicolumn{5}{|c|}{ Merkitsevyys $^{1}$} \\
\hline & & & & & & $\mathrm{K} v s \mathrm{~S}$ & $\mathrm{~K} v s \mathrm{E}$ & $\mathrm{K} v s \mathrm{SE}$ & $\mathrm{S} v s \mathrm{SE}$ & $\mathrm{E} v s \mathrm{SE}$ \\
\hline UF, C 18:0 & 18,66 & 18,26 & 17,68 & 17,48 & 0,566 & & & 0 & & \\
\hline C 18:1 trans & 2,82 & 5,14 & 2,62 & 5,27 & 0,176 & $* *$ & & $* *$ & & $* * *$ \\
\hline C $18: 1 \mathrm{cis}$ & 35,49 & 34,15 & 35,21 & 35,18 & 0,324 & $*$ & & & o & \\
\hline C 18:2cis & 3,99 & 4,45 & 4,07 & 3,25 & 0,356 & & & & $\mathrm{o}$ & \\
\hline C 18:2konj & 0,53 & 0,92 & 0,61 & 0,84 & 0,105 & o & & & & \\
\hline JL, C 18:0 & 19,20 & 18,92 & 18,95 & 17,67 & 0,553 & & & & & \\
\hline C 18:1 trans & 3,24 & 5,63 & 3,30 & 5,47 & 0,219 & $* *$ & & $* *$ & & $* *$ \\
\hline C $18: 1 \mathrm{cis}$ & 33,16 & 33,12 & 33,04 & 34,22 & 0,607 & & & & & \\
\hline C 18:2 cis & 1,55 & 1,73 & 1,50 & 1,74 & 0,104 & & & & & \\
\hline C 18:2 konj & 0,83 & 1,15 & 0,76 & 1,20 & 0,072 & $*$ & & $*$ & & $*$ \\
\hline
\end{tabular}

${ }^{1}$ o $\mathrm{p}<0,10 ; * \mathrm{p}<0,05 ; * * \mathrm{p}<0,01 ; * * * \mathrm{p}<0,001 .{ }^{2}$ Keskiarvon keskivirhe (Standard error of mean).

\section{Johtopäätökset:}

Väkirehun kasviöljylisäys muutti lihan rasvahappokoostumusta terveellisempään suuntaan eli lisäsi tyydyttymättömien rasvahappojen osuutta kokonaismäärästä. Soijaöljy lisäsi CLA:n osuutta rasvahapoista jauhelihassa merkitsevästi ja kokolihassa lievästi. Täysrehun E-vitamiini nosti lihan vitamiinitasoa, mutta ei vaikuttanut lihan värin pysyvyyteen myoglobiini- ja väriarvojen perusteella, todennäköisesti pakastuksen ja sulatuksen aiheuttaman valuman johdosta. Eläinten kasvu maltillisella väkirehuruokinnalla, keskimäärin $38 \%$ kuiva-aineen syönnistä, ja hyvälaatuisella karkearehulla oli erinomainen ja osoitti hyvän karkearehun merkityksen lihanaudan kasvatuksessa.

Kiitokset MTT:n emolehmänavetan ja Kiteen opetusteurastamon henkilökunnalle kokeen huolellisesta toteutuksesta. Dosentti Markku Honkavaaralle kiitos tuloksista käydyistä hyödyllisistä keskusteluista.

\section{Kirjallisuus:}

AOCS Official methods Ce 1c-89 (surplus 1997). Fatty acid composition by GLC cis,cis and trans isomers. In: AOCS Official methods, 5th Ed. 1998.

Bannon, C.D., Breen, G.J., Craske, J.D., Hai, N.T., Harper, N.L. \& O'Rourke, K.L. 1982. Analysis of fatty acid methyl esters with high accuracy and reliability. J. Chrom. 247: 71-89.

Enser, M., Scollan, N.D., Choi, N.J., Kurt, E., Hallett, K. \& Wood, J.D. 1999. Effect of dietary lipid on the content of conjugated linoleic acid (CLA) in beef muscle. Anim. Sci. 69: 143-146.

Griinari, M., Hissa, K. \& Ryhänen, E.-L. 2000. Dietary sunfloweroil increases conjucated linolenic acid (CLA) concentration in beef. J. Dairy Sci. 83: Suppl.1:276.

Friedel, K. 1990. Die Schätzung des energetischen Futterwertes von Grobfutter mit Hilfe einer Cellulasemethode. [The estimation of the energetic feeding value of roughages by means of cellulase method]. Wissenschaftliche Zeitung Universitet Rostock, N-Reihe 39, 78-86.

Ip, C., Singh, M., Thompson, H.J. \& Scimeca, J.A. 1994. Conjugated linoleic acid suppresses mammary carcinogenesis and proliferative activity of the mammary gland in the rat. Cancer Res. 54: 1212-1215.

Lee, K. N., Kritchevsky, D. \& Pariza, M. W. 1994. Conjugated linoleic acid and atherosclerosis in rabbits. Atherosclerosis 108: 19-25.

SAS. 1999. SAS/STAT User's Guide, Version 8, Cary, NC: SAS Institute Inc. 3809 p.

Shantha, N.C., Crum, A.D. \& Decker, E.A. 1994. Evaluation of conjugated linoleic acid concentrations in cooked beef. J. Agric. Food Chem. 42: 1757-1760.

Sheeny, P.J.A., Morrissey, P.A., Buckley, D.J. \& Wen, J. 1997. Effects of vitamins in the feed on meet quality in farm animals: Vitamin E. Recent Advances in Animal Nutrition. Ed. Garnsworthy, P.C \& Wiseman, J. p.3-27.

Tuori, M., Kaustell, K., Valaja, J., Aimonen, E., Saarisalo, E. \& Huhtanen, P. 2000. Rehutaulukot ja ruokintasuositukset. Helsinki. 88 p.

Van Soest, P.J., Robertson, J.B. \& Lewis, B.A. 1991. Methods for dietary fiber, neutral detergent fiber and nonstarch polysaccharides in relation to animal nutrition. J. Dairy Sci. 74: 3583-3597. 